\title{
RADIOCARBON DATING: A DIDACTIC VIDEOTAPE
}

\section{GEMMA RAURET, J. S. MESTRES and J. F. GARCÍA}

Radiocarbon Laboratory, University of Barcelona - Institut d'Estudis Catalans Avenida Diagonal 647, 08028 Barcelona, Spain

In recent years, audiovisual techniques have evolved to the extent that videotape is now a very useful didactic tool in any scientific field. Audiovisual presentation of radiocarbon techniques allows us to communicate with radiocarbon users at a highly scientific level. To familiarize archaeologists and other users of radiocarbon dates with the basics and experimental procedures of radiocarbon dating, we prepared a videotape that explains radiocarbon dating and liquid scintillation counting. The presentation consists of the following sections:

- Geochemistry of radiocarbon dating, involving the distribution of carbon among the different carbon reservoirs and its incorporation into plants and animals; the different carbon isotopes and the formation, distribution and decay of ${ }^{14} \mathrm{C}$.

- Measurement of ${ }^{14} \mathrm{C}$ activity by liquid scintillation, introducing the concept of activity and explaining the conversion of beta energy into light and its measurement with a liquid scintillation counter.

- Treatment of samples, showing materials suitable for ${ }^{14} \mathrm{C}$ dating and the procedure of pretreatment to eliminate non-contemporary carbon.

- Synthesis of benzene, in three steps: production of $\mathrm{CO}_{2}$, reduction to $\mathrm{C}_{2} \mathrm{H}_{2}$ and trimerization to $\mathrm{C}_{6} \mathrm{H}_{6}$, as well as the preparation of the counting solution. The complete process is explained with images of an actual synthesis and counting preparation.

- Necessity of using a contemporary standard because of the fossil-fuel effect and ${ }^{14} \mathrm{C}$-producing nuclear reactions in the atmosphere.

- Age calculation and its range. We show that radioactive decay is a random phenomenon, and that the measured activity recorded has a somewhat variable value, which later becomes the origin of the uncertainty.

- Calibration of radiocarbon ages. We point out that the ${ }^{14} \mathrm{C}$ calendar does not show true ages owing to fluctuations of the ${ }^{14} \mathrm{C}$ concentration in the atmosphere. Finally, we illustrate the calibration procedure.

Level: University

Duration: 17 min.

Languages: English, French, Spanish and Catalan

Systems: PAL-NTSC/VHS-Beta

Script and scientific direction: Gemma Rauret, J. S. Mestres and J. F. García

Directed by: Antonio R. Bartalomé

Co-producers: ICE Universitat de Barcelona - CIRIT, Generalitat de Catalunya

Legal Dept.: B 23069/89

Available from: J. Duran

Servei d'Informació i Publicacions

Universitat de Barcelona

Gran Via de les Corts Catalanes, 585

08007 BARCELONA, SPAIN

Fax: 34-3-3185267 